\title{
Currículos alinhados à Base Nacional Comum CURRICULAR (BNCC): A EXPERIÊNCIA DO MUNICÍPIO DE VIDEIRA, SC
}

\author{
ALIGNED CURRICULUMS TO CURRICULAR COMMON NATIONAL BASE \\ (BNCC): THE EXPERIENCE OF CITY OF VIDEIRA, SC
}

\begin{abstract}
(1) Camila Regina Rostirola
Doutora em Educação pela Universidade Federal do Paraná (UFPR). Atua como professora colaboradora do Programa de Pós-Graduação em Educação da Universidade do Oeste de Santa Catarina (UNOESC)

Videira, SC - Brasil camila.rostirola@unoesc.edu.br

Luiz Felipe Torcatto Zanella Mestre em Administração pela Universidade Federal de Santa Catarina (UFSC). Atua como professor na Universidade do Oeste de Santa Catarina (UNOESC) e como Secretário Municipal de Educação Videira, SC - Brasil secretaria@edu-videira.sc.gov.br
\end{abstract}

\begin{abstract}
Resumo: $\mathrm{O}$ texto relata a experiência do Município de Videira na elaboração dos currículos da educação infantil e do ensino fundamental. Analisa as orientações advindas da Base Nacional Comum Curricular, do Currículo Base do Território Catarinense e de documentos que orientam os entes federados a elaborarem e/ou reelaborarem os seus currículos. Constata que, apesar da tentativa de uniformização curricular, o Município buscou ressignificar e recontextualizar competências e habilidades de forma a atender a sua realidade, além de envolver profissionais da educação no processo de construção. Considera-se que a experiência foi bem-sucedida, pois oportunizou momentos de reflexão acerca do processo de ensino-aprendizagem e de ampliação das possibilidades políticas do currículo.

Palavras-chave: Base Nacional Comum Curricular. Currículo. Participação. Profissionais da Educação.

Abstract: The text reports the experience City of Videira about the construction of your curriculums. It analyzes orientation from the Curricular Common National Base, from the Base Curriculum of Santa Catarina Territory and the documents hat guide the federated entities to prepare and / or re-elaborate their curriculum. It notes that despite the attempt to standardization the curriculum, the municipality sought to reframe and recontextualizing competences and skills in order to attend their reality, in addition to involving all the education professionals in the process of building curriculum. It is considered that the experience was successful, because it provided moments of reflection about the teaching-learning process, and of expanding the political possibilities of the curriculum.
\end{abstract}

Keywords: Curricular Common National Base. Curriculum. Participation. Education Professionals.

\section{Para citar - ABNT NBR 6023:2018}

ROSTIROLA, Camila Regina; ZANELLA, Luiz Felipe Torcatto. Currículos alinhados à Base Nacional Comum Curricular (BNCC): a experiência do município de Videira, SC. Cadernos de Pós-graduação, São Paulo, v. 19, n. 2, p. 8396, jul./dez. 2020. Disponível em: https://doi.org/10.5585/cpg.v19n2.18460. 
Introdução

O caráter normativo da Base Nacional Comum Curricular (BNCC) torna obrigatório que os entes federados elaborem e/ou reelaborem os seus currículos, com vistas a atender ao disposto nesse documento. No entanto, faz-se relevante compreender que as competências, habilidades e objetivos de aprendizagem são comuns, mas os currículos são diferentes, pois precisam ser elaborados de acordo com a realidade local e social de cada município e instituição de ensino.

A Cidade de Videira iniciou a construção de seus documentos curriculares no ano de 2019, em razão das demandas advindas da BNCC, do Currículo Base da Educação Infantil e do Ensino Fundamental do Território Catarinense e de orientações expedidas por instituições como União Nacional de Conselhos Municipais de Educação (UNCME), União Nacional dos Dirigentes Municipais de Educação (Undime) e Federação Catarinense de Municípios (Fecam), além das oriundas de órgãos de controle, como Ministério Público/SC e Tribunal de Contas de Santa Catarina.

Nessa via, este artigo tem por objetivo relatar a experiência do Município de Videira na elaboração dos seus currículos da educação infantil e do ensino fundamental. O texto está organizado de forma a, inicialmente, apresentar as demandas advindas de documentos nacionais e estaduais acerca da revisão das propostas curriculares municipais e das escolas. Na seção seguinte apresenta-se a experiência de Videira, sendo esta subdivida em: currículo da educação infantil e currículo do ensino fundamental, em razão das especificidades de cada uma dessas etapas da educação básica. Por último, são tecidas algumas considerações finais.

\section{Demandas para a revisão das propostas curriculares municipais}

Aprovada no ano de 2017, a BNCC trata-se de um documento "de caráter normativo que define o conjunto orgânico e progressivo de aprendizagens essenciais como direito das crianças, jovens e adultos no âmbito da Educação Básica escolar.” (BRASIL, 2017, p. 7). É fruto de um processo marcado por discussões e conflitos entre diferentes instâncias e atores.

Além de ser um documento normativo, é uma "referência nacional para a formulação dos currículos dos sistemas e das redes escolares dos Estados, do Distrito Federal e dos Municípios e das propostas pedagógicas das instituições escolares [...]” (BRASIL, 2017, p. 8).

Sua elaboração foi coordenada pelo Ministério da Educação (MEC), mas contou com parcerias de associações como o Conselho de Secretários de Educação (Consed) e a Undime. A instituição de parcerias foi uma das justificativas de peso “[...] para adesão de importantes segmentos da sociedade à construção da Base e também para a elaboração final do documento." (SCHNEIDER; NARDI, 2018, p. 54). 
É importante mencionar que se construiu uma teia discursiva em torno da necessidade de construção de um documento que definisse uma BNCC. Para tal, foram evocadas as referências legais “contidas na Constituição Federal de 1988, na atual Lei de Diretrizes e Bases da Educação Nacional (LDB) n. 9.394, de 20 dezembro de 1996, e no Plano Nacional de Educação, PNE 20142014.” (SCHNEIDER; NARDI, 2018, p. 54).

O prazo estipulado, na Resolução $\mathrm{CNE} / \mathrm{CP}$ n$^{\circ}$ 2/2017, para adequação dos currículos à BNCC foi até o início do ano letivo de 2020 e exigiu a mobilização imediata dos estados e municípios brasileiros.

Em Santa Catarina, a construção do currículo iniciou no ano de 2018. Este foi escrito em regime de colaboração entre a Secretaria de Estado de Educação (SED), a Undime, o Conselho Estadual de Educação (CEE), a UNCME e a Fecam. O documento intitulado Currículo Base da Educação Infantil e do Ensino Fundamental do Território Catarinense foi homologado pela Resolução CEE/SC nº 070, no dia 17 de junho de 2019 (SANTA CATARINA, 2019).

Uma das recomendações advindas da Resolução CEE/SC nº 070 é que as escolas pertencentes às redes estaduais de ensino realizem a adesão ao documento estadual, assim como os municípios que não possuem Sistema de Ensino ${ }^{1}$ instituído por lei. Já as redes de ensino municipais com sistema de ensino instituído e as escolas privadas podem optar por aderir ao Currículo Catarinense ou construir seu próprio referencial curricular atendendo ao que determina a Resolução $\mathrm{CNE} / \mathrm{CP}^{\circ}{ }^{\circ} 2 / 2017$.

Cabe mencionar que Santa Catarina possui 295 municípios, e apenas 12 não possuem sistema de ensino instituído em forma de lei. Diante dessa situação, apesar de o movimento de construção e implementação do currículo do território catarinense envolver uma rede de governança que contempla associações como Undime, UNCME e Fecam, buscando, assim, uma unicidade na proposta curricular, ficou aos municípios a incumbência de decidir pela adesão ou elaboração de seu próprio documento.

É salutar destacar que, além da exigência advinda das Resoluções nacional e estadual, os municípios estão sendo notificados por órgãos de controle, como o Tribunal de Contas e o Ministério Público, acerca da necessidade de revisar/construir documentos curriculares adequados à BNCC.

Videira entendeu que era necessário elaborar seus próprios documentos, com vistas a ampliar as possibilidades políticas do currículo e realizar as suas inserções de modo a recontextualizar e extrapolar o proposto pela BNCC. 


\section{A experiência do município de Videira}

Videira é um Município do Estado de Santa Catarina e está situado no Vale do Rio do Peixe. Segundo as estimativas do IBGE (2019), conta com uma população de 53.065 habitantes. Possui nove escolas municipais e 19 centros municipais de educação infantil, totalizando, aproximadamente, 6.000 matrículas.

No Município de Videira, especificamente no que tange às instituições educacionais pertencentes ao sistema municipal de ensino, o processo de elaboração/reorganização dos currículos atrelados às novas demandas educacionais advindas da BNCC ganharam força no ano de 2019, apesar de o documento ter sido homologado em dezembro de 2017.

No ano de 2018 foram realizadas reuniões, precedidas pela equipe pedagógica da Secretaria Municipal de Educação (SME), com vistas a estudar e analisar a BNCC. É salutar destacar que, inicialmente, buscou-se, conjuntamente com os professores, compreender os fundamentos, a estrutura e a organização desse documento, assim como analisar de forma crítica as suas proposições.

Nesse ano pairava um campo de incertezas, pois muito se falava na adequação curricular. Não obstante, quem estava de fato envolvido com o processo de ensino-aprendizagem possuía muitas dúvidas acerca desse procedimento. Além disso, os municípios não sabiam se a BNCC realmente seria implementada, em decorrência das eleições presidenciais.

Entre os anos de 2018 e 2019, uma representação dos profissionais da educação do Município participaram da elaboração das Diretrizes Curriculares da Associação dos Municípios do Alto Vale do Rio do Peixe (AMARP). Tal iniciativa foi realizada por via da contratação de consultorias educacionais e da elaboração de documentos que servissem de orientação curricular para os 15 municípios que integram essa Associação. A Diretriz Curricular dos anos iniciais da AMARP foi finalizada no ano de 2018, e a dos anos finais, em 2019. Ambos os documentos serviram de consulta para o Município de Videira.

No ano de 2019, o Estado de Santa Catarina construiu e aprovou o seu Currículo Base da Educação Infantil e do Ensino Fundamental do Território Catarinense, e uma representante da Secretaria Municipal de Educação de Videira participou desse processo. O documento foi homologado pela Resolução CEE/SC n 070.

No entanto, além de contar com a BNCC, o Currículo Base da Educação Infantil e do Ensino Fundamental do Território Catarinense e as Diretrizes Curriculares dos Municípios da AMARP, o Município sentia a necessidade de construir um documento que de fato retratasse a sua realidade educacional e os anseios dos seus profissionais de educação. 
Em face a essas questões, em 2019 iniciou-se o processo de construção dos currículos da educação infantil e do ensino fundamental. Em discussão com os professores e a equipe pedagógica, foi consensual que os documentos deveriam ser denominados de currículos, e não de propostas, referenciais e/ou diretrizes curriculares.

Essa opção ocorreu em virtude de que municípios e estados já contavam com a BNCC, documento que compunha o que a legislação denomina de base nacional, logo os entes federados deveriam elaborar a sua parte diversificada, ou seja, elementos específicos que caracterizassem as especificidades do Município, dos alunos, dos professores e das famílias. A preocupação era justamente elaborar um documento que fosse além do que o nacional previa, ou seja, extrapolar e construir um currículo.

A SME, bem como os profissionais de educação não gostariam de incorrer em um documento que apenas atendesse aos interesses da uniformização curricular, das avaliações em larga escala e de um conceito de qualidade muito mais atrelado às demandas mercadológicas (FREITAS, 2016; MACEDO, 2016, 2018).

Mesmo sabendo que, em razão de a BNCC ser um documento normativo e que, por mais que o município elaborasse o seu próprio documento, estaria trabalhando com "variações sobre o mesmo tema" (FREITAS, 2016), a construção do currículo trata-se de uma oportunidade de estudar e analisar criticamente por onde caminham as novas políticas curriculares, assim como de contribuir, ainda que de forma ínfima, para amenizar as desigualdades educacionais e propor um projeto educacional que busque a formação integral dos educandos da educação básica.

A intenção na elaboração dos documentos municipais era justamente realizar a recontextualização do documento nacional, de forma a atender aos anseios e às especificidades locais. Sentiase a necessidade de que os professores compreendessem essa nova forma de organização curricular em forma de competências e que não ficassem na dependência da interpretação de outrem, mas que pudessem ler, compreender e tecer suas próprias considerações.

$\mathrm{Na}$ via da produção contextual do currículo, no Município de Videira, a SME foi responsável por conduzir o processo de construção e implementação dos currículos da educação infantil e do ensino fundamental. É importante mencionar que o Município não contou com financiamento para realização de tal processo, nem com consultorias educacionais, todos os trabalhos relacionados à elaboração dos currículos foram efetuados por profissionais que atuam na rede municipal.

\section{O currículo da educação infantil}

Com vistas a elaborar o currículo da educação infantil, institui-se, no ano de 2019, um Grupo de Trabalho (GT) com representantes dos professores, gestores e equipe pedagógica. Os 
encontros foram organizados, inicialmente, pensando em propor momentos de estudo dos principais documentos que balizam a organização curricular nessa etapa da educação básica. Os integrantes sentiram uma fragilidade teórica nos escritos da BNCC e demonstravam preocupação acerca de uma possível antecipação do processo de escolarização caso não fosse elaborado um documento que retratasse a real finalidade da educação infantil.

Após a constituição do GT, deu-se início ao processo de produção do texto. Os membros do GT reuniam-se semanalmente e elaboravam textos prévios, os quais eram sistematizados pela equipe da SME e enviados para análise e contribuições dos demais profissionais que atuam nos centros municipais de educação infantil. É importante destacar que os escritos iniciaram com as concepções e fundamentos teóricos, haja vista que serão estes que darão subsídios para pensar nos organizadores curriculares.

No Município adotou-se a definição de currículo proposta pelas Diretrizes Curriculares Nacionais para a Educação Infantil, a qual o caracteriza

\begin{abstract}
como um conjunto de práticas que buscam articular as experiências e os saberes das crianças com os conhecimentos que fazem parte do patrimônio cultural, artístico, ambiental, científico e tecnológico, de modo a promover o desenvolvimento integral de crianças de 0 a 5 anos de idade. (BRASIL, 2009, p. 19).
\end{abstract}

Como forma de complementar essa definição, foi solicitado aos professores que traduzissem para o cotidiano da sala de aula o que significava um currículo para a educação infantil.

Documento que norteia o planejamento e o trabalho realizado em sala.

Organização, dia a dia da escola, rotina e planejamento.

É o que define a organização do planejamento contendo experiências, metodologias e estratégias.

Documento que deve nortear o trabalho em sala de aula, oportunizando o desenvolvimento integral dos alunos/crianças.

São todas as experiências vivenciadas e internalizadas pelas crianças, permitem o acesso aos conhecimentos necessários para o desenvolvimento integral das crianças.

É um documento que irá nortear as práticas, as ações e o direcionamento a partir da nossa realidade. Deve ser adequado à BNCC, mas voltado para nosso contexto. (VIDEIRA, 2019a, p. 15).

Com base nas contribuições dos participantes do GT, foi possível identificar que o currículo representava um norte, ou seja, um caminho para direcionar o trabalho do professor. Partindo dessa prerrogativa, buscou-se compreendê-lo como um documento orientador, mas que integra as dimensões humanas, sociais e culturais que são específicas de cada sociedade e instituição escolar.

Os esforços da equipe pedagógica da SME, no âmbito do GT, estiveram voltados para que o currículo não fosse concebido apenas como um documento prescritivo, ou seja, propositor de 
listas de atividades e de aprendizagens, mas que de fato representasse e traduzisse o cotidiano das instituições educacionais.

Além da construção dos textos que comporiam o currículo, foi solicitado aos professores que elaborassem atividades com os educandos, pois a ideia era que estes também colaborassem com o documento. As contribuições das crianças vieram em forma de desenho e representaram, principalmente, como elas concebem o espaço educacional, além de serem úteis para que os profissionais tecessem algumas reflexões a respeito da importância dessa etapa da educação básica. Os desenhos integraram o currículo, conjuntamente com os textos.

O currículo da Educação Infantil deve ser pensado por todos os profissionais, assim como pelas próprias crianças. Trata-se de dar voz e conceber a criança como sujeito de direitos e partícipes do processo de ensino-aprendizagem, assim como da sua própria cultura (OLIVEIRA, 2011).

Após a fase de elaboração dos fundamentos do currículo, o GT passou a trabalhar na construção dos organizadores curriculares, ${ }^{2}$ os quais foram pensados seguindo as orientações propostas pela BNCC. O esforço dos integrantes desse grupo era justamente recontextualizar o documento nacional de modo a atender a realidade do Município e pensar nas especificidades da educação infantil.

Apesar de não conseguir se desvencilhar de muitas amarras impostas pela BNCC, o desejo era aproveitar esse momento e elaborar um currículo vivo e em movimento, assim como exercitar o pensar criticamente dos profissionais da educação, pois

\footnotetext{
[...] não precisamos de mais um documento de gaveta e que retrate a distância entre os formuladores e executores das políticas educacionais, mas sim de um currículo que seja significativo, que retrate as necessidades e especificidades da nossa Educação Infantil e vise à melhoria da qualidade social da Educação Infantil videirense. (VIDEIRA, 2019a, p. 14).
}

Com o texto prévio finalizado, os professores foram convidados para um dia de formação, com vistas a estudar e realizar as adequações necessárias na versão preliminar do documento. Os grupos foram divididos respeitando a faixa etária em que atuam.

Nesse dia, a proposta de trabalho aos profissionais que atuam na educação infantil foi estudar os objetivos de aprendizagem e desenvolvimento propostos pela BNCC e recontextualizálos para a realidade educacional do Município de Videira. Além desse processo, novos objetivos de aprendizagem e desenvolvimento foram elaborados, com o intuito de inserir a parte diversificada no documento. 
Desse encontro resultaram inúmeras sugestões com relação aos organizadores curriculares. Foi um momento oportuno para que a equipe pedagógica pudesse sanar as dúvidas dos professores, assim como para que estes sentassem com os seus pares e discutissem assuntos relacionados ao processo de ensino-aprendizagem.

Um aspecto interessante foi que esse momento de estudo foi coordenado pelos professores que participavam do GT, culminando, assim, em um importante momento de formação e troca de experiência entre os pares.

Após a realização desse encontro, as contribuições dos professores foram sistematizadas e uma versão preliminar do currículo foi encaminhada para as instituições educacionais. A prerrogativa era de que todos os profissionais pudessem realizar mais uma leitura e verificar se, de fato, os seus anseios estavam contemplados e retratados no documento.

Uma vez finalizado o documento, ele foi submetido ao CME para aprovação. O Currículo da Educação Infantil do Município de Videira foi homologado por via da Resolução nº 005/2019, e a sua implementação foi prevista para o início do corrente ano (VIDEIRA, 2019b).

Um aspecto que merece destaque nesse processo de construção do currículo está voltado à adesão e participação de representantes das escolas privadas de educação infantil. A SME, em parceria com o CME, realizou reuniões com os responsáveis por essas instituições educacionais e propôs que se juntassem à rede municipal e agregassem as suas contribuições ao documento, uma vez que se faz necessário pensar na educação do Município.

É importante mencionar que das seis instituições privadas de educação infantil, quatro realizaram adesão ao currículo municipal. As demais elaboraram os seus documentos e os submeteram ao CME para aprovação.

Atualmente, a equipe pedagógica da SME vem auxiliando as instituições de educação infantil na revisão de seus projetos pedagógicos, haja vista que, apesar de o Município elaborar um currículo que possa ser comum, cada instituição vai dar o seu tom, considerando as necessidades e especificidades que são próprias de cada local.

Paralelamente ao GT e aos momentos de estudo realizados nos Centros de Educação Infantil, as formações continuadas realizadas no ano de 2019 e no início de 2020 foram pensadas com vistas a trabalhar o novo currículo, pois no município existe a rotatividade de professores, ou seja, muitos não participaram dos momentos de estudo destinados à construção do documento curricular.

A implementação desse documento vai ser realizada paulatinamente, e a cada início de ano letivo novas formações precisam ser pensadas, a fim de que todos os profissionais sejam conhecedores desse documento. 
De forma geral, considera-se a experiência de construção do currículo da educação infantil um momento ímpar para o Município, haja vista que os professores puderam participar e organizar um documento que fosse ao encontro da sua realidade cotidiana. Para a educação infantil, construir um currículo foi pensar com sensibilidade e levar em conta as experiências, aprendizagens, vivências, interações e brincadeiras, sem, contudo, perder de vista a especificidade dessa etapa da educação básica.

\section{O currículo do ensino fundamental}

No ensino fundamental, a organização do currículo envolveu todos os profissionais e seguiu uma metodologia diferenciada da proposta na educação infantil. Tal iniciativa ocorreu em decorrência da complexidade e das mudanças advindas da BNCC para essa etapa da educação básica.

Os professores dos anos iniciais do ensino fundamental foram organizados de acordo com as turmas/anos em que atuam, e os professores dos anos finais, por componente curricular. Os encontros foram realizados entre o segundo semestre do ano de 2019 e o início de 2020, nas dependências da SME. É importante destacar que em 2018 foram realizados alguns encontros com esse público, no entanto apenas com o intuito de estudar a BNCC.

O objetivo, nessa etapa da educação básica, também se voltava para a elaboração de um documento intitulado currículo e para proporcionar aos docentes uma análise crítica da BNCC e das novas orientações curriculares. De forma geral, o intuito era informar aos profissionais as ideologias que subjazem esse documento, as quais estabelecem um vínculo imediato entre educação e desenvolvimento econômico, assim como "a valorização do caráter salvacionista da educação [...], a redução da educação a níveis de aprendizagem e ao fornecimento de garantias sociais de que todos os alunos e as alunas terão credenciais/padrões de aprendizado uniformes” (LOPES, 2018, p. 23), além da "suposição de que os docentes não sabem o que fazer nas escolas sem uma orientação curricular comum.” (LOPES, 2018, p. 23).

A equipe da SME, no primeiro encontro, realizou uma reflexão sobre as funções do currículo e das ideologias que marcam as propostas curriculares, principalmente no que tange ao papel da escola na contemporaneidade, uma vez que:

O currículo nunca é apenas um conjunto neutro de conhecimentos que, de algum modo, aparece nos textos e nas salas de aula de uma nação. É sempre parte de uma tradição seletiva, da seleção de alguém, da visão de algum grupo de conhecimento legítimo. $\mathrm{O}$ currículo é produto das tensões, conflitos e compromissos culturais, políticos e econômicos que organizam e desorganizam um povo. (APPLE, 1999, p. 51). 
Pensando dessa forma, o currículo não se trata apenas de prescrições, mas de um documento fruto da construção coletiva e participativa. Nessa via, buscou-se, nos encontros, elucidar os interesses e entender o novo enfoque pedagógico proposto pela BNCC. Além de mobilizar os profissionais do Município para que fosse possível desvencilhar o currículo dos interesses mercadológicos e pensar na formação humana e social dos educandos, ou seja, fazer uso desse documento e da prática pedagógica a serviço de um projeto educacional diferenciado.

Os professores, nos primeiros encontros, demonstravam muita resistência em elaborar um documento que fosse ao encontro do que propunha a BNCC e questionavam se os educandos conseguiriam acompanhar o quantitativo de conteúdos escolares e se teriam condições de aprender, em razão da antecipação de conteúdos e habilidades.

Outro aspecto discutido foi o enfoque pedagógico proposto a partir de competências gerais e específicas. Schneider e Nardi (2018, p. 55) destacam dois interesses relacionados ao enfoque pedagógico: "primeiro, de salvaguardar o alinhamento com o modelo curricular das avaliações em larga escala. O segundo, de demonstrar que não se trata de uma posição nacional sobre a necessidade desse alinhamento, mas do praticado em avaliações internacionais das quais o Brasil participa."

As avaliações em larga escala e os livros didáticos são instrumentos utilizados com o objetivo de forçar estados e municípios a implementar a BNCC. Não obstante, não se pode incorrer na prerrogativa de estreitar o currículo apenas aos aspectos que são avaliados, mas, sim, recontextualizar e ressignificar esse documento de acordo com as demandas do Município de Videira e com o compromisso da melhoria da qualidade da educação.

É importante mencionar que o Município se encontrava em um grande dilema, pois possuía a obrigatoriedade de elaborar um documento que atendesse ao disposto na BNCC, mas não concordava com muitos aspectos e ideologias dispostos do documento nacional. Nessa via, trabalhouse com a possibilidade de inserir as contribuições dos profissionais da educação no currículo.

Os grupos realizaram estudos da BNCC e de artigos que buscavam embasar teoricamente as discussões sobre o currículo. Apesar de o Município não realizar a adesão ao Currículo Base para a Educação Infantil e Ensino Fundamental do Território Catarinense, este foi objeto de estudo, pois não se pode desconsiderar que a Cidade está inserida nesse território.

Foram, em média, cinco encontros com cada um dos grupos, além dos momentos de estudo nas escolas. Os grupos de professores convergiram em algumas questões de ordem organizacional do documento, como da necessidade de manter os códigos alfanuméricos ${ }^{3}$ da BNCC, de elaborar unidades temáticas e habilidades que são próprias do município e catalogá-las com um 
código próprio, além de fazer menção de forma mais detalhada aos conteúdos que poderiam ser trabalhados em cada uma das habilidades.

A definição dos conteúdos esteve atrelada à necessidade de garantir aos profissionais segurança no que ensinar. Os professores entenderam que, caso estes não fossem definidos, ficariam abertos à interpretação de cada profissional, o que poderia desencadear conflitos entre as escolas de uma mesma rede.

Nesse lume, os organizadores curriculares do Ensino Fundamental seguem a orientação proposta pela BNCC, ou seja, estão pautados nas 10 competências gerais para a educação básica e nas cinco áreas de conhecimento. Estão organizados de forma a, inicialmente, realizar uma abordagem teórica sobre cada componente curricular, e, posteriormente, a descrição das unidades temáticas (para os componentes de Arte, Ciências, Educação Física, Ensino Religioso, Geografia, Matemática e História), das práticas de linguagem (para os componentes de Língua Portuguesa e Língua Inglesa), dos objetos de conhecimento, das habilidades nacionais e das habilidades elaboradas pelos professores da rede municipal de ensino, além dos conteúdos.

Figura 1 - Exemplo de organizador curricular

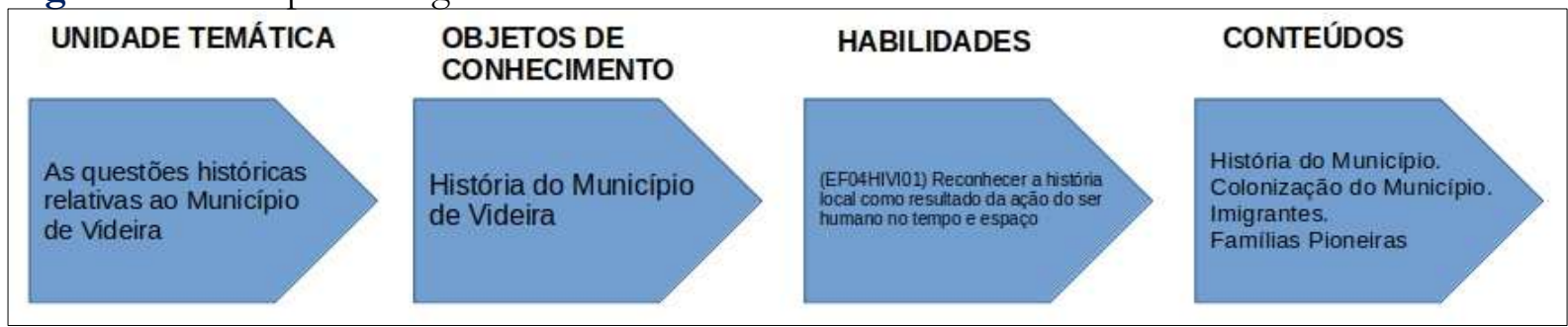

Fonte: Adaptada de Videira (2020a).

Para as habilidades elaboradas pelos profissionais, um código alfanumérico próprio foi criado, com o intuito de sinalizar as especificidades locais, ou seja, a parte diversificada do currículo. É salutar mencionar que não foi realizada uma divisão entre a base comum e a parte diversificada, mas feito um esforço na tentativa de entrelaçar as inserções nacionais e as locais.

Ainda, os organizadores curriculares contemplam temas e saberes que envolvem as dimensões histórica, política, social, cultural, econômica e ética, os chamados temas transversais contemporâneos, os quais são advindos da BNCC, de legislações e também das especificidades que circundam as escolas e seus entornos. Além dos mencionados no currículo, entende-se que outros poderão ser acrescentados em função de novas demandas ou por escolha das próprias escolas.

O currículo de Videira extrapola o proposto na BNCC, na medida em que propõe competências, habilidades e conteúdos relacionados à parte diversificada, tendo em vista a necessidade de atender às peculiaridades locais e, ainda, por pensar na educação enquanto prática social e política. 
Uma vez finalizado o currículo, este foi encaminhado para que os professores pudessem realizar uma última leitura e verificar se ainda era necessário realizar mais algum ajuste. É interessante destacar que foram recebidas inúmeras sugestões e que estas foram agregadas ao documento final.

O currículo do ensino fundamental foi instituído via Resolução do CME nº 005/2020 no mês de março do corrente ano. Trata-se de "um documento orientador das atividades escolares, que busca concretizar diferentes formas de uso dos tempos e espaços pedagógicos [...]” (VIDEIRA, 2020b, p. 1), além de garantir as aprendizagens essenciais previstas na BNCC.

Com a aprovação do currículo, os esforços da equipe pedagógica da SME estarão voltados para auxiliar na elaboração dos planejamentos, assim como na revisão dos PPPs das instituições educacionais.

É interessante mencionar que, apesar de o Município elaborar um currículo único, não é possível que ele seja colocado em prática de forma igual em todas as escolas, pois sempre será interpretado de formas diferentes.

O currículo só vai ser significativo se for ao encontro das necessidades e especificidades de cada realidade educacional. Logo, "as políticas curriculares não se resumem apenas a propostas e práticas enquanto documentos escritos, mas incluem os processos de planejamento, vivenciados e reconstruídos em múltiplos espaços e por múltiplas singularidades no corpo social da educação.” (BRASIL, 2013, p. 24).

Considera-se que o currículo se trata de uma construção social, ou seja, é pensado para atender às necessidade e especificidades de um determinado contexto histórico, político, social e cultural, assim como de projetos societários. Dessa forma, o currículo de Videira nasce da consolidação de diferentes formas de pensar e de fazer o processo educativo, é fruto de uma construção coletiva e democrática, "que busca não apenas definir prescrições de conteúdos a serem ensinados e aprendidos, mas pensar em uma educação e, consequentemente, em práticas educativas reflexivas, críticas e libertadoras.” (VIDEIRA, 2020a, p. 9).

Apesar de no ensino fundamental o currículo estar muito arraigado ao proposto pela BNCC, acredita-se que não se pode abrir mão de elaborar os próprios documentos, a fim de que os professores possam tirar suas próprias conclusões e não dependam das de outrem.

\section{Considerações finais}

O processo de elaboração dos currículos da rede municipal de Videira foi marcado pela possibilidade de participação de todos os profissionais da educação. Nessa perspectiva, é possível 
afirmar que tanto na educação infantil quanto no ensino fundamental os documentos foram construídos a muitas mãos.

Apesar de a BNCC ter posto limitações aos entes federados e às instituições educacionais, a experiência tratou-se de uma oportunidade de estudo e reflexão, assim como para contextualizar as orientações curriculares dada a realidade educacional. Os esforços da SME e dos professores concentraram-se nesse sentido, ou seja, em elaborar um documento de forma coletiva e que, mesmo com a tentativa de homogeneização curricular, retratasse os anseios dos profissionais e dos educandos e ampliasse as possibilidades políticas do currículo.

Os currículos do Município extrapolam a BNCC, sem, contudo, promover uma fragmentação entre a base comum e a parte diversificada. De forma geral, é importante ressaltar que, mesmo com todas as críticas e lacunas da BNCC, os entes federados e, principalmente, as escolas possuem a obrigatoriedade de implementá-la. Assim, buscou-se, no documento do Município de Videira, amenizar o seu caráter utilitarista e aproximar as orientações curriculares das suas necessidades.

\section{Notas}

${ }^{1}$ Para Saviani (1999, p. 125), cabe a cada "município decidir entre as três possibilidades previstas na LDB, a saber: a) instituir o próprio sistema de ensino; b) integrar-se ao sistema estadual de ensino; c) compor com o estado, no âmbito de seu território, um sistema único de educação básica." Santa Catarina, ainda, possui municípios que são vinculados ao Sistema Estadual de Ensino.

${ }^{2}$ No Município de Videira intitula-se organizadores curriculares a parte do currículo que trata da organização dos objetivos de aprendizagem e desenvolvimento e das habilidades por faixa etária (educação infantil) e por ano e componente curricular (ensino fundamental).

${ }^{3}$ Os códigos alfanuméricos são compostos por letras e números. Servem para catalogar os objetivos de aprendizagem e as habilidades previstas no currículo do Município, a exemplo da BNCC.

\section{Referências}

APPLE, Michael W. Políticas Culturais e Educação. Porto: Porto Editora, 1999.

BRASIL. Lei ñ 9.394, de 20 de dezembro de 1996. Estabelece as diretrizes e bases da educação nacional. Diário Oficial da União, Brasília, DF, 21 dez. 1996. Disponível em: http:/ /www.planalto.gov.br/ccivil_03/leis/19394.htm. Acesso em: 31 mar. 2020.

BRASIL. Ministério da Educação. Diretrizes Curriculares Nacionais Gerais da Educaşão Básica. Brasília: MEC, SEB, DICEI, 2013.

BRASIL. Ministério da Educação. Secretaria de Educação Básica. Base Nacional Comum Curricular. Brasília, DF: MEC, 2017. Disponível em: http://basenacionalcomum.mec.gov.br/wpcontent/uploads/2018/06/BNCC_EI_EF_110518_versaofinal_site.pdf. Acesso em: 30 mar. 2020.

BRASIL. Resolução no 5, de 17 de dezembro de 2009. Fixa as Diretrizes Curriculares Nacionais para a Educação Infantil. Brasília, DF, 2009. Disponível em: http://www.seduc.ro.gov.br/portal/legislacao/RESCNE005_2009.pdf. Acesso em: 30 mar. 2020. 
FREITAS, Luiz Carlos. Desconstruindo a "base que não é currículo". Avaliação Educacional - Blog do Freitas, 24 ago. 2016. Disponível em: https://avaliacaoeducacional.com/2016/08/24/desconstruindo-a-base-que-nao-e-curriculo/. Acesso em: 2 abr. 2020.

IBGE. Cidades e Estados. Videira. Brasília, DF: IBGE, 2019. Disponível em: https://www.ibge.gov.br/cidades-e-estados/sc/videira.html. Acesso em: 10 abr. 2020.

LOPES, Alice Casimiro. Apostando na produção contextual do currículo. In: AGUIAR, Márcia Angela da S. DOURADO, Luiz Fernandes (org.). A BNCC na contramão do PNE 2014- 2024: avaliação e perspectivas. Recife: ANPAE, 2018. p. 31-36.

MACEDO, Elizabeth. A Base é a Base. E o currículo o que é? In: AGUIAR, Márcia Angela da S. DOURADO, Luiz Fernandes (org). A BNCC na contramão do PNE 2014- 2024: avaliação e perspectivas. Recife: ANPAE, 2018. p. 28-33.

MACEDO, Elizabeth. Base nacional curricular comum: a falsa oposição entre conhecimento para fazer algo e conhecimento em si. Educ. rev., v. 32, n. 2, p. 45-68, 2016.

OLIVEIRA, Zilma Ramos de. Educação infantil: fundamentos e métodos. 7. ed. São Paulo: Cortez, 2011.

SANTA CATARINA. Currículo Base da Educação Infantil e do Ensino Fundamental do Território Catarinense. Secretaria de Estado da Educação, 2019.

SAVIANI, Dermeval. Sistemas de ensino e planos de educação: O âmbito dos municípios. Educação \& Sociedade, ano XX, n. 69, dez. 1999

SCHNEIDER, Marilda Pasqual; NARDI, Elton Luiz. Pilares Estruturantes da Base Nacional Comum Curricular da Educação Brasileira: Subordinação à Agenda Global. Revista de Estudos Curriculares, v. 9, n. 1, 2018.

VIDEIRA. Currículo da Educação Infantil. Secretaria Municipal de Educação, 2019a.

VIDEIRA. Currículo do Ensino Fundamental. Secretaria Municipal de Educação, 2020a.

VIDEIRA. Resolução no 005-2019. Institui o Currículo da Educação Infantil do Município de Videira. Conselho Municipal de Educação, 2019b.

VIDEIRA. Resolução ñ 005-2020. Institui o Currículo do Ensino Fundamental do Município de Videira. Conselho Municipal de Educação, 2020b. 